\title{
Duration of Isoniazid Prophylaxis in HIV-Infected Individuals Living In Endemic Areas of Tuberculosis
}

\section{Roberto A Accinelli*}

Instituto de Investigaciones de la Altura Universidad Peruana Cayetano Heredia Lima, Lima, Peru

Patients with HIV infection represent a substantial fraction of the total population of patients with active tuberculosis infection. In 2008, approximately 709,000 (7.7\%) of new tuberculosis disease cases and 200,000 tuberculosis-related deaths were estimated to have occurred in HIV positive individuals. In the developing world, tuberculosis has emerged as the most common opportunistic infection and the leading cause of death in HIV infected patients [1]. In regions where tuberculosis is prevalent, $44 \%$ of HIV patients could develop tuberculosis in the absence of preventive therapy or HAART [2].

Currently available strategies to prevent tuberculosis are effective. In 10 trials of tuberculosis prevention including a total of 5762 patients with HIV infection, preventive therapy was associated with a $32 \%$ overall reduction in the risk of developing active tuberculosis. In the four trials examining the efficacy of isoniazid therapy for HIV infected individuals with a positive tuberculin skin test, the rates of prevention were even better, $62 \%$ [3]. These impressive results have generated broad consensus supporting effective treatment of latent tuberculosis in HIV infected patients. In the current ATS/CDC guidelines, the authors recommend that all patients with HIV infection diagnosed with latent TB should receive treatment, and, when isoniazid is chosen, the duration of treatment should be extended to nine months rather than six [4].

However, accumulating evidence suggests these recommendations may not be sufficient. In a study of isoniazid administered to HIV positive patients with a positive or anergic tuberculin skin test in Uganda, Johnson et al. found that the protection conferred by isoniazid was lost a year after therapy. Similar findings were reported by Quigley et al. who found that, compared with the protection observed during isoniazid therapy, the protection was lower in the 1.5 to 2.5 years after completion of therapy and was absent after 2.5 years [5]. Samandari et al. reported that a 36 month course of isoniazid prophylaxis reduced the incidence of tuberculosis by $43 \%$ compared with a 6 month course [6]. Recently, Churchyard et al. showed that mass screening and treatment for latent tuberculosis in continuously exposed workers in South African gold mines reduced the rates of active tuberculosis by $58 \%$ while the workers were taking isoniazid but these effects were lost after therapy was stopped [7]. And Rangaka et al. found that the effect of isoniazid in HIV people treated for 12 months was greatest when they are still on treatment $(\mathrm{HRu}=0.52)$, than between $12-23$ months $(\mathrm{HRu}=0.61)$ and for 24 or more months $(\mathrm{HRu}=0.78)$, but without statistical signification [8].

With these results we proposed to give permanently INH for HIV people living in an TB endemic area, as Peru, as primary prophylaxis when CD4 counts less than 200 cells/ml or if there is a history of oropharyngeal candidiasis and as secondary prophylaxis for HIV patients with previous TB disease for lifelong, unless reconstitution of the immune system occurs, similar to the recommendation in use in all the world for prevention of Pneumocystis [9].

\section{References}

1. Martinson NA, Barnes GL, Moulton LH, Msandiwa R, Hausler H, et al. (2011) New regimens to prevent tuberculosis in adults with HIV infection. $N$ Engl $J$ Med 365: 11-20.

2. Raviglione MC, Narain JP, Kochi A (1992) HIV-associated tuberculosis in developing countries: clinical features, diagnosis, and treatment. Bull World Health Organ 70: 515-526

3. Akolo C, Adetifa I, Shepperd S, Volmink J (2010) Treatment of latent tuberculosis infection in HIV infected persons. Cochrane Database Syst Rev 1: CD000171.

4. [No authors listed] (2000) Targeted tuberculin testing and treatment of latent tuberculosis infection. This official statement of the American Thoracic Society was adopted by the ATS Board of Directors, July 1999. This is a Joint Statement of the American Thoracic Society (ATS) and the Centers for Disease Control and Prevention (CDC). This statement was endorsed by the Council of the Infectious Diseases Society of America. (IDSA), September 1999, and the sections of this statement. Am J Respir Crit Care Med 161: S221-247.

5. Quigley MA, Mwinga A, Hosp M, Lisse I, Fuchs D, et al. (2001) Long-term effect of preventive therapy for tuberculosis in a cohort of HIV-infected Zambian adults. AIDS 15: 215-222.

6. Samandari T, Agizew TB, Nyirenda S, Tedla Z, Sibanda T, et al. (2011) 6-month versus 36-month isoniazid preventive treatment for tuberculosis in adults with HIV infection in Botswana: a randomised, double-blind, placebo-controlled trial. Lancet 377: 1588-1598.

7. Churchyard GJ, Fielding KL, Lewis JJ, Coetzee L, Corbett EL, et al. (2014) A trial of mass isoniazid preventive therapy for tuberculosis control. N Engl J Med 370: 301-310.

8. Rangaka MX, Wilkinson RJ, Boulle A, Glynn JR, Fielding K, et al. (2014) Isoniazid plus antiretroviral therapy to prevent tuberculosis: a randomised double-blind, placebo-controlled trial. Lancet 384: 682-690.

9. Limper AH, Knox KS, Sarosi GA, Ampel NM, Bennett JE, et al. (2011) An Officia American Thoracic Society Statement: Treatment of Fungal Infections in Adult Pulmonary and Critical Care Patients. Am J Respir Crit Care Med 183: 96-128.

*Corresponding author: Roberto A Accinelli, Instituto de Investigaciones de la Altura Universidad Peruana Cayetano Heredia Lima, Lima, Peru, Tel: 51998119480; E-mail: roberto.accinelli@upch.pe

Received March 27, 2015; Accepted May 04, 2015; Published May 12, 2015

Citation: Accinelli RA (2015) Duration of Isoniazid Prophylaxis in HIV-Infected Individuals Living In Endemic Areas of Tuberculosis. J AIDS Clin Res 6: 456 doi:10.4172/2155-6113.1000456

Copyright: () 2015 Accinelli RA. This is an open-access article distributed under the terms of the Creative Commons Attribution License, which permits unrestricted use, distribution, and reproduction in any medium, provided the original author and source are credited. 